\title{
A ECONOMIA SOLIDÁRIA E SUA EXPANSÃO NA MESORREGIÃO DO TRIÂNGULO MINEIRO E ALTO PARANAÍBA - MG
}

\author{
Geisa Daise Gumiero Cleps \\ Universidade Federal de Uberlândia, Instituto de Geografia, Professora dos Cursos de Graduação e Pós- \\ Graduação, Uberlândia, MG, Brasil \\ gdgumiero@ufu.br \\ Paulo Henrique Silva de Amorim \\ Universidade Federal de Uberlândia, Instituto de Geografia, Graduação em Geografia, Uberlândia, MG, Brasil \\ paulohamr@gmail.com
}

\begin{abstract}
RESUMO
A Economia Solidária, enquanto alternativa aos princípios da acumulação capitalista, promove novas formas de organização de produção e de relações sociais que, sob a ótica da Geografia, realizam-se a partir dos inúmeros atores e seus vários interesses que se difundem no território. A proposta começa a ganhar força a partir da segunda metade da década de 1990, manifestando valores antigos que fazem jus a esse tipo de organização, como: solidariedade, igualdade social, responsabilidade e autogestão. A comercialização de produtos e serviços que resultam a partir dessa prática são de grande importância na geração de emprego e renda para vários grupos sociais. Por isso, faz-se necessária uma análise mais aprofundada da economia solidária, já que a comercialização não acontece sob tendências de acumulação, mas como fonte de redistribuição de recursos, a fim de proporcionar melhores condições de vida aos indivíduos responsáveis pelos Empreendimentos Econômicos Solidários (EES). Dentro desse contexto, objetivamos, no presente trabalho, analisar a localização, a caracterização e a forma de organização dos EES presentes na mesorregião do Triângulo Mineiro e Alto Paranaíba em Minas Gerais a partir de dados obtidos no Cadastro Nacional de Economia Solidária e Comércio Justo (CADSOL).
\end{abstract}

Palavras-chave: Economia Solidária (ES). Empreendimentos Econômicos Solidários (EES). Mesorregião Triângulo Mineiro e Alto Paranaíba.

\section{THE SOLIDARITY ECONOMY AND ITS EXPANSION IN THE MESORREGIÃO OF TRIÂNGULO MINEIRO AND ALTO PARANAÍBA - MG}

\begin{abstract}
The Solidarity economy, as an alternative to the principles of capitalist accumulation, promotes new forms of organization and social relations that, from the point of view of geography, is carried out from the numerous actors and their various interests which spreads throughout the territory. The proposal begins to gain momentum from the second half of the 1990s, manifesting old values that justify this type of organization, such as: solidarity, social equality, responsibility and self-management. The commercialization of products and services resulting from this practice is of great importance in generating and income for various social groups. For this reason, it is important to carry out a more in-depth analysis of the solidarity economy, since commercialization does not take place under tendencies of accumulation, but as a source of redistribution of resources to provide better living conditions for those responsible, by Empreendimentos Econômicos Solidários (EES). Within this context, we aim, in the present work, to identify the location, the characterize and the form the organization of the EES present in the mesoregion of the Triângulo Mineiro e Alto Paranaíba in state of Minas Gerais from data obtained by Cadastro Nacional de Economia Solidária e Comércio Justo (CADSOL).
\end{abstract}

Keywords: Solidarity Economy (ES). Solidarity Economy Enterprises (EES). Mesoregion of Triângulo Mineiro and Alto Paranaíba. 


\section{INTRODUÇÃO}

Nas últimas duas décadas, um processo que vem se tornando bastante evidente no Brasil é a crescente formação de empreendimentos que se baseiam em atividades de livre associação. Este, segundo Gaiger (2011), é um fenômeno a ser observado, em diferentes sociedades, como alternativa que se traduz à constante crise do desemprego, fundamentado em princípios que se baseiam na autogestão, na cooperação e na solidariedade. As mudanças introduzidas pelo novo padrão de acumulação alteram a realização de novos e diferentes negócios que encontram no âmbito da Economia Solidária (ES) uma alternativa para a inclusão social, para a geração de emprego e de renda.

Entende-se por Economia Solidária a prática baseada no trabalho coletivo, junto a associações, a grupos informais e a cooperativas que prezam pela solidariedade, cujo resultado final do trabalho tem como característica principal a humanização das atividades desenvolvidas nos empreendimentos econômicos solidários (SINGER, 2003, p.254). Essa humanização baseia-se nos princípios de divisão do trabalho como fator de equidade entre os membros do grupo.

Ainda de acordo com Singer (2003, p. 116),

O conceito (Economia Solidária) se refere a organizações de produtores, consumidores, poupadores, etc., que se distinguem por duas especificidades: (a) estimulam a solidariedade entre os membros mediante a prática da autogestão e (b) praticam a solidariedade para com a população trabalhadora em geral, com ênfase na ajuda aos mais desfavorecidos.

Ainda que alguns autores se debrucem para definir o conceito de Economia Solidária, tornando-o cada vez mais próximo de uma consolidação, observa-se que o tema tem sido objeto de estudo de várias áreas do conhecimento científico. Nesse sentido, convém compreender sua importância por se colocar contra os princípios básicos do capitalismo como, por exemplo, a acumulação de capital e a individualidade presente entre as classes.

O sistema capitalista não se apresenta como um modo de produção hegemônico, sobretudo no processo de globalização a qual pode ser considerada como um dos principais propulsores das mudanças ocorridas nas últimas décadas, pois, a partir das diferentes formas e usos, representa um processo dinamizador e central na reorganização do espaço geográfico.

No bojo dessas transformações que se apresentam com grande veemência, Santos (2000) demonstra que o processo de globalização constitui uma resultante da emergência do meio técnico-científicoinformacional a partir das mudanças na organização social em nível global. $O$ autor reforça que o fluxo de mercadorias, de capital, de pessoas e de informação, parte da atuação conjunta de grandes agentes corporativos. E que estes últimos se baseiam em usos políticos e econômicos que vão moldando o território e, consequentemente, contribuindo para a manutenção de desigualdades sociais e econômicas que asseguram a reprodução do capitalismo.

Concomitantemente a difusão de formas produtivas, a economia solidária também surge como alternativa de produção, distribuição, circulação e consumo de mercadorias, pela qual a cooperação e a autogestão comunitária entre os associados contribuem com ações diferentes das que são verificadas no circuito superior da economia capitalista que, de acordo com Santos (2004), é aquele resultante da modernização tecnológica, representado por monopólios nacionais e internacionais, composto por atividades vinculadas ao meio técnico-científico-informacional. Enquanto que o circuito inferior caracteriza-se por atividades em pequena escala e de baixo grau de especialização, menos capitalista e de expressão local ou mesmo regional, resultado da divisão territorial do trabalho. Nesse sentido, as atividades desenvolvidas por grande parte dos empreendimentos de economia solidária, compõem o circuito inferior da economia.

Sobre essa questão, Cattani (2003, p. 44) destaca que:

[...] inserida como política de estado, a Economia Solidária tem promovido, ainda que de maneira incipiente, a reprodução do capital em detrimento da realização das classes sociais mais baixas. Isso porque as mudanças no quesito estrutural têm se apresentado como escassas para suportar as densas modificações e os rebatimentos marcantes no território, reforçando o caráter conflituoso do modelo econômico vigente.

A partir dessa realidade, observamos que o tema em questão exige grande esforço de reflexão, a fim de que sejam aprofundadas análises das relações sociais que difundem o nosso objeto de estudo. Para isso, no presente artigo, buscamos identificar a localização e a caracterização dos Empreendimentos Econômicos Solidários (EES) existentes na mesorregião do Triangulo Mineiro e Alto Paranaíba que, sob a 
dinâmica sócio-territorial, apresentam formas de organização com características singulares para cada tipo de empreendimento.

Para a elaboração deste, fez-se um levantamento de dados acerca do tema - Economia Solidária - na mesorregião do Triângulo Mineiro e Alto Paranaíba a fim de relacionar com os dados obtidos através da quantificação dos empreendimentos solidários identificados e relacionados através do site da Secretaria Nacional de Economia Solidária (SENAES) e do Cadastro Nacional de Economia Solidária e Comércio Justo (CADSOL). A partir da formação de um banco de dados, passou-se a analisar as características dos empreendimentos existentes na referida mesorregião, a espacialização dos mesmos e a importâncias desses para os grupos que se dedicam a esta prática como forma de sobrevivência e alternativa de emprego e renda.

No que concerne ao referencial teórico, foram importantes os levantamentos bibliográficos que proporcionaram suporte para a análise dos Empreendimentos Econômicos Solidários. Entre os autores utilizados destacam-se Paul Singer, Luiz Inácio Gaiger, David Cattani entre outros, que muito contribuíram intelectualmente no desenvolvimento da pesquisa. Este artigo, fruto dessas investigações, apresenta-se estruturado em três partes. Na primeira realizamos uma análise da economia solidária no Brasil, em seguida, apresentamos a expansão da economia solidária no estado de Minas Gerais e, na terceira parte, são apresentadas as principais características dos empreendimentos econômicos solidários existentes na Mesorregião do Triângulo Mineiro e Alto Paranaíba. Por fim, apresentamos as considerações finais e as referências utilizadas.

\section{A ECONOMIA SOLIDÁRIA NO BRASIL}

No Brasil a Economia Solidária se instala como resposta ao desemprego que o assolava durante a década de 1990. Naquele contexto, o país resolveu adotar o modelo econômico neoliberal, ocasionando a abertura de novas áreas de investimento para o capital amplamente seletivo e planejado, seguindo os trilhos de uma economia globalizada. Essa medida, por sua vez, resultou na organização de grupos sociais que buscavam alternativas para solucionar o problema e, nesse contexto, optaram pela criação de empreendimentos sustentados por quatro princípios básicos: trabalho coletivo, solidariedade, autogestão e desenvolvimento de uma atividade econômica.

Rompendo com a hierarquização dos espaços de trabalho informal, essa iniciativa deve ser compreendida num momento em que esses grupos, ao perceberem que o Estado brasileiro reduziria os gastos públicos em setores sociais, viram-se obrigados a buscar novos campos de trabalho, já que com a predestinada obsolescência de empresas e indústrias tinha criado um grande número de trabalhadores desempregados. Observa-se que a "Economia Solidária surge como resposta à crise na forma de numerosas iniciativas locais" (FRANÇA FILHO, 2006, p. 68).

O exército de mão de obra (Marx, 1968), reserva do mercado de trabalho na década de 1990, contribuiu para que as práticas da Economia Solidária fossem amadurecidas, difundidas e viabilizadas em todo o país enquanto uma alternativa emancipadora entre os sujeitos envolvidos. Vários trabalhadores que estavam excluídos socialmente do mercado de trabalho formal se inseriram nessa prática, contribuindo na criação de uma economia horizontal, com dimensões menores e (des)polarizadas do sistema econômico vigente.

Corroborando com essa afirmativa, Paul Singer (2003, p.86) escreveu que:

[...] a economia solidária constitui um modo de produção que, ao lado de diversos outros modos de produção, compõe a formação social capitalista, que é capitalista porque o capitalismo não só é o maior modo de produção, mas molda a superestrutura legal e institucional de acordo com os seus valores e interesses. Mesmo sendo hegemônico, o capitalismo não impede o desenvolvimento de outros modos de produção, porque é incapaz de inserir dentro de si toda população economicamente ativa.

Observa-se, assim, que a Economia Solidária se tornou uma possibilidade de progresso que se traduz em melhores condições de vida a partir da acessibilidade à alimentação, à moradia, à renda, à educação, à equidade etc., para indivíduos que se encontravam à margem do capitalismo que impunha péssimas condições aos seus empregados, sob o domínio das empresas que polarizavam o mercado de trabalho e de produção.

É importante compreender que "a especificidade dos trabalhadores e trabalhadoras inseridos na economia solidária compõe uma parcela da sociedade que vive em miséria e pobreza extrema" (SINGER, 2001, p. 188), constituindo uma articulação contrária ao processo histórico do capitalismo. É por isso que se torna

$\begin{array}{llllll}\text { Caminhos de Geografia } & \text { Uberlândia - MG } & \text { v. 19, n. } 67 & \text { Set/2018 } & \text { p. 349-360 } & \text { Página } 351\end{array}$


imprescindível o aprofundamento de discussões no entorno da temática. Ressalta-se que, o meio acadêmico tem se mobilizado em torno da discussão da Economia Solidária com redes universitárias que têm como objetivo atender e apoiar as camadas mais baixas da população na formação, capacitação e inserção de cooperativas, associações e grupos informais em diversos ramos do trabalho solidário, inclusive com a criação de incubadoras que prestam auxílio e assistência na criação e na regulamentação de novos empreendimentos.

Ainda que os resultados produtivos obtidos a partir desta forma de organização econômica se apresentem de maneira incipiente, deve-se considerar que têm sido significativos no desenvolvimento humano e social das classes sociais mais baixas, em grande maioria dos estados brasileiros. A relevância da prática econômica e solidária, como um fator preponderante frente ao atual modelo de acumulação capitalista, além da expansão por meio de usos e formas que moldam o território de vários países em desenvolvimento, sobretudo no Brasil, reforça sua emancipação como forma de trabalho que flexibiliza e atende aos princípios de autogestão e de equidade dos indivíduos que se inserem nesta forma de organização.

De acordo com os dados da Secretaria Nacional de Economia Solidária (SENAES) para o ano de 2010, no Brasil, o número de indivíduos inseridos nessa prática econômica, ultrapassava um milhão de associados, com aproximadamente vinte e quatro mil Empreendimentos Econômicos Solidários. Baseando-se nesses números, observa-se a expansão de atividades que se originam a partir dos empreendimentos desde a produção, a comercialização e o crédito, com famílias e associações participando em todas as etapas do processo.

Dentre as atividades criadas, algumas ganham destaque como o artesanato, a produção de insumos agrícolas, de reciclagem, de produção de gêneros alimentícios entre outros, reforçando o papel transformador através da sua disseminação no território. É inegável o crescimento, bem como as ações de incentivo ao desenvolvimento da economia solidária no país, que se constitui como realidade na vida de muitos brasileiros. Observa-se que a expansão desta forma de organização tem sido cada vez mais emancipatória com a participação de grupos, resultando na geração de emprego e renda a partir das atividades desenvolvidas nas cooperativas, associações, grupos informais e sociedades mercantis que conferem sustento à Economia Solidária no país e em Minas Gerais.

\section{EXPANSÃO DA ECONOMIA SOLIDÁRIA EM MINAS GERAIS}

Alguns fatores atuais como, por exemplo, a introdução de novas tecnologias no processo de produção, a falência de empresas e indústrias, as privatizações e a globalização, fundamentam e estimulam a criação de livres associações e de autogestão, já que esses fatores contribuem para elevar as taxas de desemprego em vários países desenvolvidos ou não.

A expansão da economia solidária é uma realidade presente em todos os estados brasileiros em virtude do apoio concedido através de instâncias federais, estaduais e, em alguns casos, municipais. Com relação aos incentivos federais, cabe destacar a criação do Fórum Brasileiro de Economia Solidária (FBES), que tem como objetivo promover a mobilização e a articulação do movimento da economia solidária em todo o país, apoiando os Empreendimentos Econômicos Solidários, além de entidades que colaboram na formação, capacitação e inserção de diversos ramos do trabalho solidário, como a Secretaria Nacional de Empreendimentos Econômicos Solidários (SENAES), do extinto Ministério do Trabalho e Emprego (MTE).

Essa expansão só foi possível devido à atuação do Estado brasileiro que criou várias condições de estímulo para a transformação do trabalho informal em postos de trabalho formal, através da expansão de políticas públicas de inclusão social (SILVA, E. E.; BORBA, E. L.; MACHADO, J. C, 2016). A partir dessa iniciativa, a economia solidária torna-se uma prática econômica que vem se consolidando por meio de incentivos, de programas e leis das três esferas governamentais (federal, estadual e municipal).

Em 2004 foi criado o Programa Nacional de Economia Solidária (PNES) com o objetivo de introduzir políticas públicas específicas, de ordem federal, que pudessem atuar em nível de estados e municípios. Em Minas Gerais, como resultado de reinvindicações de grupos que praticavam atividades nos moldes da economia solidária, o governo criou a Lei Estadual n 15.028 de 19 de abril de 2004, instituindo a Política Estadual de Fomento à Economia Popular Solidária no Estado de Minas Gerais.

Um ano após a formalização da economia solidária, o estado de Minas Gerais ocupava a $3^{a}$ posição no ranking de números de EES da região Sudeste (superado pelo estado de São Paulo e o do Rio de Janeiro), com $14 \%$ do total de empreendimentos da região, de acordo com os dados fornecidos SENAES em 2005. Tomando como base as informações divulgadas pelo Atlas de Economia Solidária para o ano

$\begin{array}{llllll}\text { Caminhos de Geografia } & \text { Uberlândia - MG } & \text { v. 19, n. 67 } & \text { Set/2018 } & \text { p. 349-360 } & \text { Página } 352\end{array}$


de 2007, o estado mineiro se destacava na $2^{2}$ posição regional com 1.236 EES, sendo superado apenas pelo Rio de Janeiro. Convém destacar que os números apresentados pelo SENAES, para o ano de 2005, restringia apenas algumas mesorregiões do estado mineiro, como: Noroeste de Minas, Vale do Jequitinhonha e Vale do Mucuri, Região Metropolitana de Belo Horizonte e Sul de Minas.

Para as demais mesorregiões do estado, como a do Triângulo Mineiro e Alto Paranaíba, não foi catalogado, naquela ocasião, nenhum EES. Tal fato reforça a necessidade de relacionar as informações obtidas com certa ressalva, pois, conforme observado nas pesquisas de campo realizadas, desde 1990 constata-se a presença de empreendimentos solidários em mesorregiões que não foram mapeadas. Contudo, há que se mencionar que o mapeamento não foi concluído devido à falta de recursos financeiros, e muitos empreendimentos não foram quantificados, o que dificulta uma análise mais aprofunda para aquele ano.

Através desses números, observa-se que, mesmo havendo distorções quanto à posição correta do estado mineiro na classificação por número de empreendimentos na região Sudeste, foi possível identificar um aumento considerável de cooperativas, de associações e de grupos sociais que veem na Economia Solidária uma alternativa de ganhos para se inserir no mercado de trabalho, ainda que verse à categoria informal.

Os dados do CADSOL (2017) revelam que, para aquele ano, existiam 1.561 EES. Destes, 311 empreendimentos localizavam-se na Mesorregião Metropolitana de Belo Horizonte, 294 no Norte de Minas, 196 na Zona da Mata, 191 no Triângulo Mineiro e Alto Paranaíba, 146 na Mesorregião Campos da Vertente, 103 no Vale do Mucuri e no Vale do Rio Doce, 69 na Sul/Sudoeste de Minas, 64 no Noroeste de Minas, 55 no Jequitinhonha, 32 empreendimentos no Oeste de Minas, e dois na Central Mineira, conforme demostrado na figura 1.

Os números mencionados anteriormente revelam as diversidades e particularidades regionais existentes no estado. Existem regiões de Minas Gerais cuja economia apresenta diferente dinamismo nos setores primário, secundário e terciário. Com destaque a este último, verifica-se que o cooperativismo representa um quadro mais expressivo, principalmente em municípios de menor população, decorrente de questões histórico-culturais que sustentam as experiências de economia solidária em atividade.

Figura 1: Minas Gerais - Empreendimentos Econômicos Solidários, por Mesorregiões (2017)

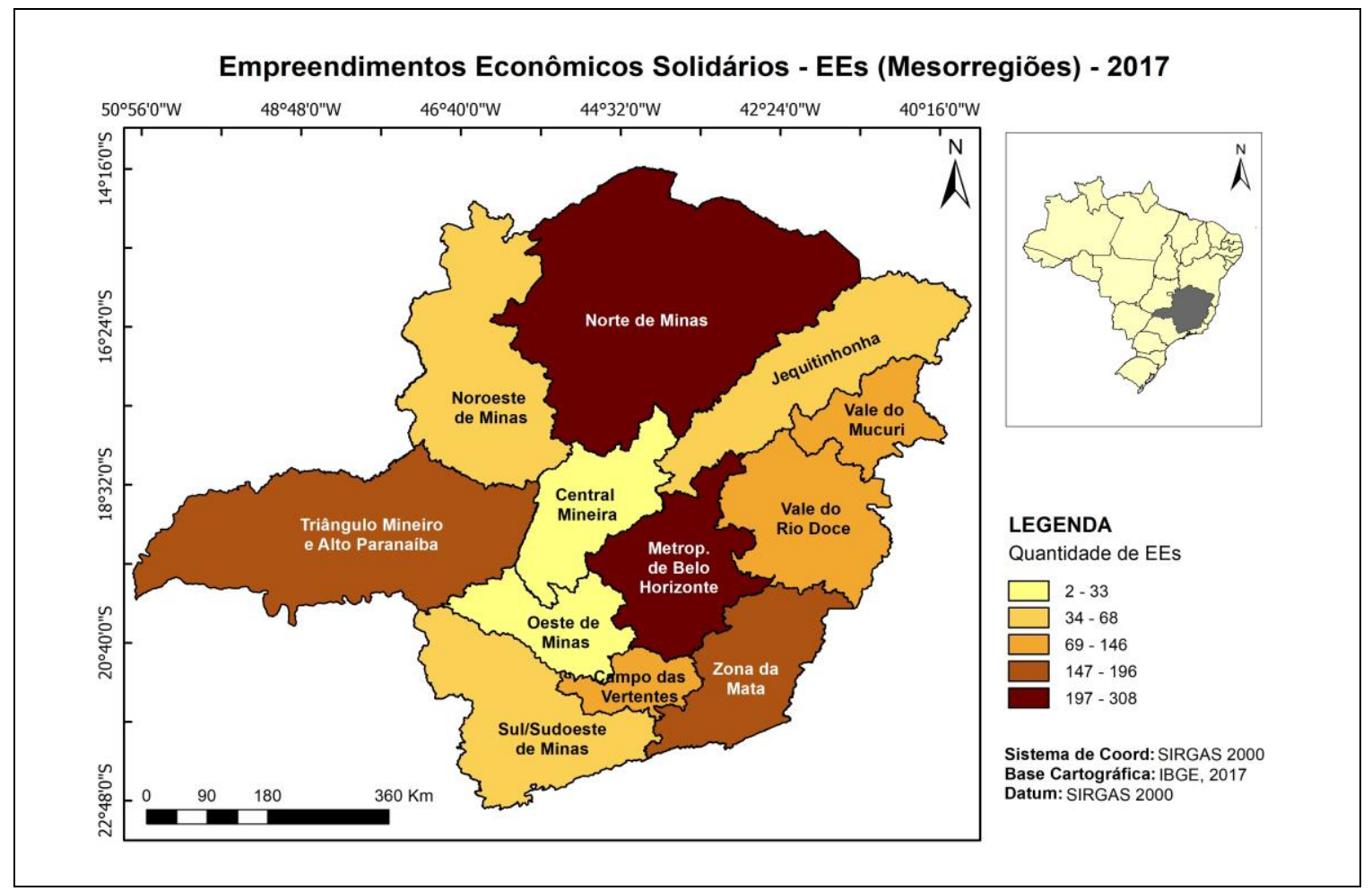

Fonte: CADSOL (2017) Elaboração: Autores (2018)

$\begin{array}{llllll}\text { Caminhos de Geografia } & \text { Uberlândia - MG } & \text { v. 19, n. } 67 & \text { Set/2018 } & \text { p. 349-360 } & \text { Página } 353\end{array}$


As Mesorregiões da Zona da Mata, Norte de Minas e Triângulo Mineiro/Alto Paranaíba destacam-se como as que possuem o maior número de associados (19.658, 10.434 e 7.158, respectivamente), de acordo com os números apresentados pelo CADSOL (2017).

Nas regiões onde existe maior número de EES, observa-se que os mesmos contam com ajuda e apoio de incubadoras de universidades públicas, que têm se dedicado a estudos, pesquisas e extensão; e de organizações não governamentais. Tais instituições sustentam a prática e incentivam eventos como feiras de economia solidária, cursos sobre administração dos empreendimentos, técnicas agroecológicas, cursos de extensão e rodas de conversas que objetivam a socialização de trocas de experiências e formas de produção e comercialização de procedência solidária.

Ao analisar a participação por gênero nos empreendimentos de Minas Gerais, observa-se que o número de mulheres é ligeiramente superior ao de homens, conforme gráfico 1, totalizando-se 30.152 mulheres $(50,2 \%)$ e 29.905 homens cadastrados $(49,8 \%)$, de acordo com dados do Cadastro Nacional de Empreendimentos Econômicos Solidários e Comércio Justo (CADSOL, 2017). Em números absolutos, são 247 mulheres a mais.

Os dados revelam ainda que onde há o predomínio de mulheres, os empreendimentos incluem atividades de produção artesanal de polpas de sucos de frutas; comércio varejista de suvenires, bijuterias e artesanatos; confecção de bordados; fabricação de biscoitos e bolachas. Enquanto que onde os homens representam a maioria, principalmente em empreendimentos rurais, prevalecem as associações de produtores rurais; agricultores familiares e cooperativas de crédito rural que envolvem a produção de horticulturas e hortifrutigranjeiros entre outros. Mesmo na prática da economia solidária, há uma forte divisão de atividades nas quais o gênero prevalece na escolha da produção.

Gráfico 1: Minas Gerais - Número de Associados por Gênero, 2017.

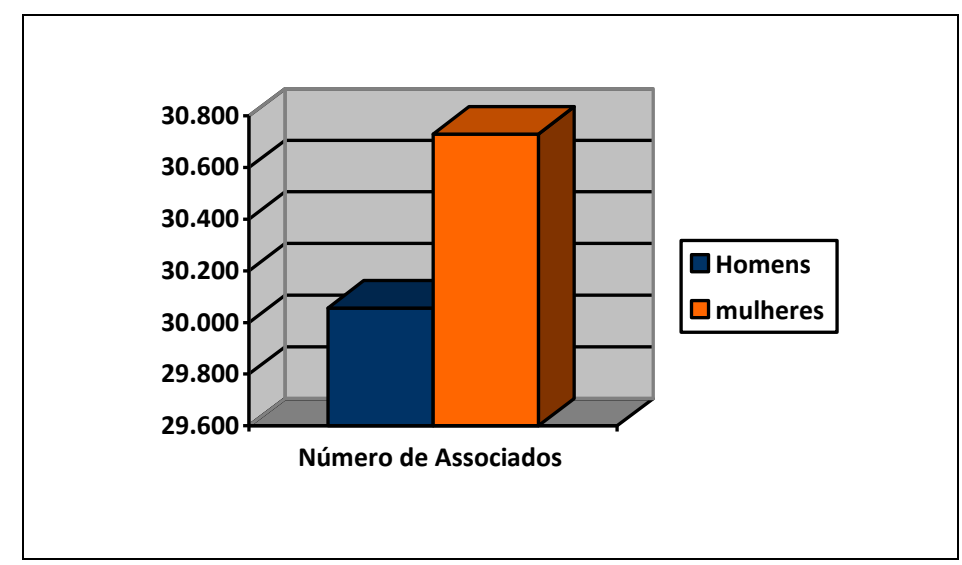

Fonte: CADSOL (2017) Elaboração: Autores (2018)

Em Minas Gerais, a distribuição regional dos empreendimentos econômicos solidários reflete a concentração populacional, a falta de postos de trabalho formal e o consequente índice de desemprego, principalmente no setor secundário da economia. Revelam as especificidades de cada lugar. Para compreender melhor essas particularidades, apresenta-se a seguir um estudo sobre os empreendimentos da Mesorregião do Triângulo Minero e Alto Paranaíba.

\section{CARACTERIZAÇÃO DOS EMPREENDIMENTOS ECONÔMICOS SOLIDÁRIOS DA MESORREGIÃO DO TRIÂNGULO MINEIRO E ALTO PARANAÍBA}

Entre as mesorregiões de Minas Gerais, destacamos como recorte deste artigo a mesorregião do Triângulo Mineiro e Alto Paranaíba, em virtude da expansão de EES cadastrados verificados através do CADSOL. Essa mesorregião apresenta-se como uma das mais dinâmicas e ricas do Estado. Sua economia está diretamente ligada ao setor primário. Ressalta-se também o setor terciário, apresentando importantes empresas de comércio atacadista, shoppings centers e grandes redes varejistas, de serviços de educação, de saúde entre outros, o que se deve à sua localização geográfica no interior do país e, 
principalmente, à presença de importantes rodovias que ligam a mesorregião a outras regiões e estados vizinhos.

Na mesorregião do Triângulo Mineiro e Alto Paranaíba, a quantidade de EES é expressiva e merece uma reflexão particular. No contexto do estado mineiro, em relação ao ano de 2007, observam-se alterações no âmbito da Economia Solidária as quais estão associadas a problemas relacionados à elaboração de novos levantamentos realizados pela SENAES, uma vez que os empreendimentos presentes no Triângulo Mineiro e Alto Paranaíba têm sua origem ainda na década de 1990 e só foram mapeados no levantamento de 2007, através das pesquisas que resultaram no primeiro mapeamento de Empreendimentos Econômicos Solidários do estado.

No primeiro estudo realizado por Silva e Cleps, em 2011, foram identificados e registrados apenas 66 empreendimentos na Mesorregião do Triângulo Mineiro e Alto Paranaíba. Estes, em sua grande maioria, encontrados nos municípios de Uberlândia, Patos de Minas e Uberaba.

A dificuldade em pesquisar os EES da mesorregião deve-se a vários fatores. Destaca-se que a grande maioria das cooperativas e associações, que hoje compõe o quadro estadual de EES, não detinha conhecimento sobre a criação da Secretaria Nacional de Economia Solidária, do Ministério do Trabalho e Emprego, a qual tinha como missão: "difundir e fomentar a economia solidária em todo o Brasil, dando apoio político e material às iniciativas do Fórum Brasileiro de Economia Solidária” (SINGER, 2003, p. 04).

Muitos empreendimentos, que funcionavam nos moldes da economia solidária, desconheciam a existência de uma legislação que pudesse respaldar e oficiar as atividades por eles desenvolvidas. Para um grande número, apesar da prática, não havia conhecimento e informação sobre os procedimentos necessários para o cadastro do empreendimento. Contudo, a experiência vivenciada por estes grupos fortaleceram e enriquecem a prática da economia solidária no estado mineiro.

A Figura 2, a seguir, com dados atualizados para o ano de 2017, apresenta a quantidade de empreendimento para cada microrregião entreposta à mesorregião em análise.

Figura 2: Triângulo Mineiro/Alto Paranaíba - Empreendimentos Econômicos Solidários (2017)

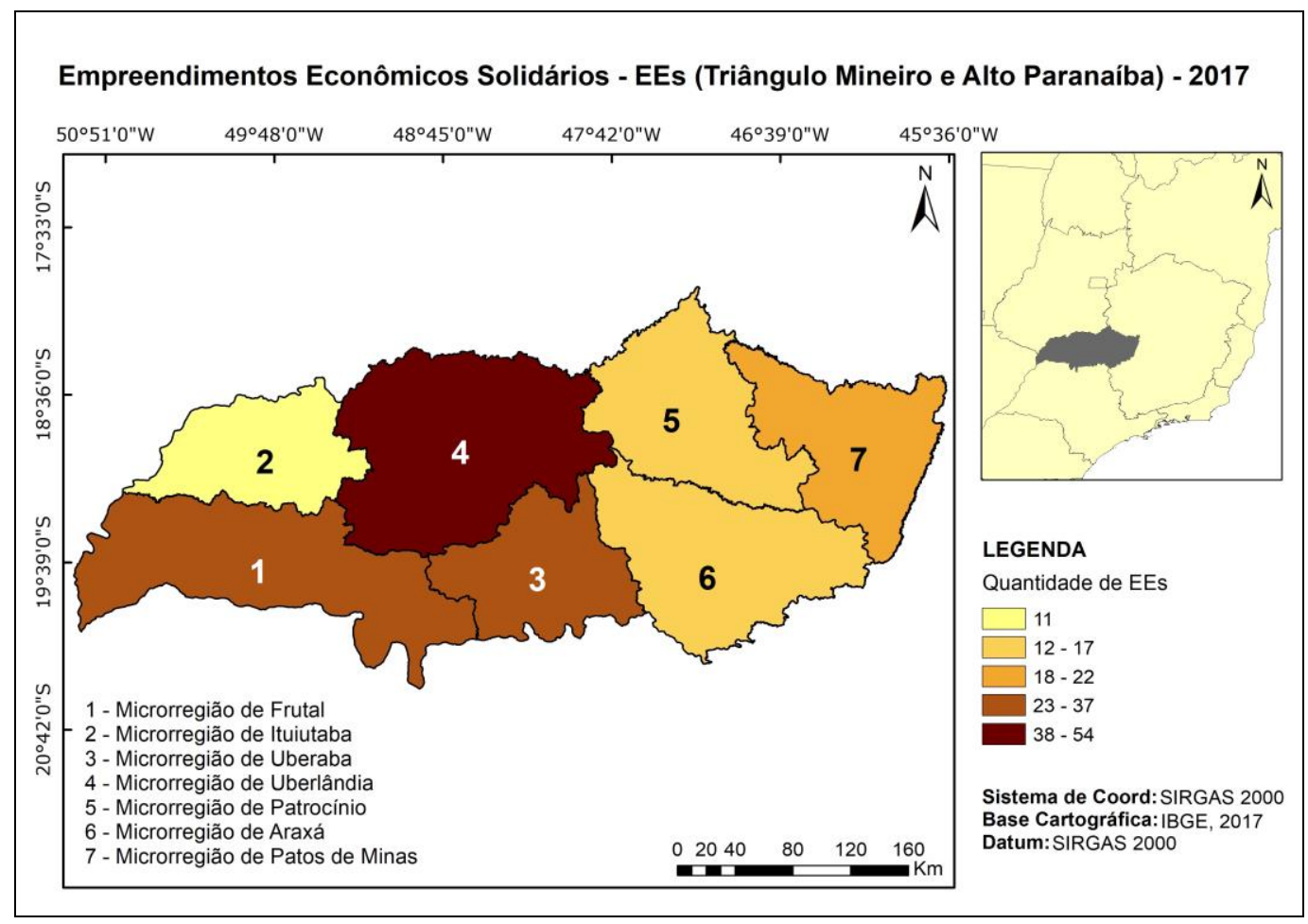

Fonte: CADSOL (2017) Elaboração: Autores (2018) 
Para o ano de 2017, conforme mencionado anteriormente, a Mesorregião do Triângulo Mineiro e Alto Paranaíba contava com 191 empreendimentos cadastrados (CADSOL, 2017). Pode-se observar, de acordo com a Figura 2, que a microrregião de Uberlândia (composta pelos municípios de Araguari, Araporã, Canápolis, Cascalho Rico, Centralina, Indianópolis, Monte Alegre de Minas, Prata, Tupaciguara e Uberlândia) possui 54 EES cadastrados, destacando-a em relação às demais microrregiões que compõem a referida mesorregião. Tal justificativa se deve, em grande parte, pela importância que o município de Uberlândia vem adquirindo nos últimos anos, dinamizando sua atual configuração, propiciando apoio mais consolidado na formação, capacitação e inserção de cooperativas e associações em diversos ramos do trabalho solidário dos municípios próximos.

Além disso, cabe destacar o aumento significativo no número de EES pelo acesso mais flexível dos indivíduos que compõem essa forma de organização de trabalho solidário com valores de igualdade e equidade. Além de direcionar a atenção em relação à quantificação dos EES, deve-se compreender que esse crescimento revela também o aumento da população excluída pelo modo de produção capitalista, bem como o aumento no número de desempregados no mercado de trabalho.

Consistem, portanto, em oportunidades resultantes por essa nova forma de economia que a aproxima pessoas que desejam um trabalho e o convívio social. Seu princípio, baseado principalmente na solidariedade, permite que o desenvolvimento vital não esteja apenas voltado aos produtores, mas também para os consumidores e todos aqueles que integram e participam da cadeia produtiva e da economia solidária.

Cabe ressaltar que, melhorada a cadeia produtiva, haverá, consequentemente, disponibilidade de produtos e serviços de qualidade, além de reajuste nos preços, adequando à mercadoria e à mão de obra necessária para a sua produção, bem como aos insumos utilizados para sua fabricação. Isso se deve em razão de que a maioria dessas mercadorias é artesanal e demandam maior tempo e esforço do indivíduo no que se refere à confecção/produção, à comercialização, principalmente se os esses empreendimentos estiverem localizados nos espaços rurais e a comercialização dos produtos ocorrer nos distritos urbanos.

Vários são os motivos que levam os associados a criarem os Empreendimentos Econômicos Solidários. Na mesorregião em análise, a principal razão apontada por 30,3\% dos empreendimentos é a criação de emprego, portanto, uma alternativa ao desemprego. Esta afirmação reforça o caráter excludente e seletivo da economia formal. A Tabela 1 apresenta os principais motivos de criação de EES na mesorregião de estudo, de acordo com as informações inseridas pelos responsáveis pelos empreendimentos no Cadastro Nacional de Economia Solidária e Comércio Justo, em 2017.

Tabela 1: Motivos de criação dos Empreendimentos Econômicos Solidários (EES) na Mesorregião do Triângulo Mineiro e Alto Paranaíba (2017)

\begin{tabular}{lcc}
\hline \multicolumn{1}{c}{ Motivos de criação dos EES } & Número de EES & $\%$ \\
\hline Uma alternativa ao desemprego & 174 & $30,3 \%$ \\
\hline Uma fonte complementar de renda para os associados & 111 & $19,3 \%$ \\
\hline Desenvolvimento de uma atividade onde todos são donos & 96 & $16,7 \%$ \\
\hline Desenvolvimento comunitário de capacidades e potencialidades & 69 & $12 \%$ \\
\hline Obtenção de maiores ganhos num empreendimento associativo & 57 & $9,9 \%$ \\
\hline Motivação social, filantrópica ou religiosa & 36 & $6,2 \%$ \\
\hline Condição exigida para ter acesso a financiamentos e apoios & 24 & $4,1 \%$ \\
\hline Outros & 6 & $1 \%$ \\
\hline TOTAL & $\mathbf{5 7 3}$ & $\mathbf{1 0 0} \%$ \\
\hline
\end{tabular}

Fonte: CADSOL (2017)

Elaboração: Autores (2018)

$\begin{array}{llllll}\text { Caminhos de Geografia } & \text { Uberlândia - MG } & \text { v. 19, n. } 67 & \text { Set/2018 } & \text { p. 349-360 } & \text { Página } 356\end{array}$


É importante destacar também que 19,3\% destes empreendimentos apontaram como motivo de criação a complementação de renda. Este fato reforça a precarização do trabalho formal, os baixos salários e a importância da economia solidária como uma alternativa para a sobrevivência de vários grupos sociais. $\mathrm{O}$ terceiro fator identificado com $16,7 \%$ foi o "desenvolvimento de uma atividade onde todos são donos". Isto, de certa forma, retira o foco central da atividade apenas da preocupação com o capital, principalmente se associado ao fato de grande parte dos indivíduos terem afirmado que um dos motivos que os levaram a participar do meio solidário foi à possibilidade de adquirir potencialidades $(12 \%)$. Outras razões foram destacadas tais como a obtenção de maiores ganhos (9,9\%); motivação social, filantrópica ou religiosa $(6,2 \%)$; acesso a financiamentos e apoios $(4,1 \%)$.

Dessa maneira, é possível perceber que, independente dos motivos, são variantes as necessidades para se integrar a essa nova forma de organização econômica. O encontro com os princípios solidários e a opressão imposta pelo atual modelo de acumulação, tanto no quesito social quanto no econômico, resulta na busca por alternativas de renda e trabalho que prezam pela justiça e equidade entre os indivíduos.

Um dos princípios norteadores da Economia Solidária é o trabalho coletivo. De acordo com os dados apresentados na Tabela 2, observa-se que $43 \%$ dos EES são formados por grupos informais; $28,7 \%$ por cooperativas; $20,4 \%$ pelas associações; e 7,3\% representam as sociedades mercantis como formas de organização dos empreendimentos localizados na Mesorregião do Triângulo Mineiro e Alto Paranaíba (CADSOL, 2017).

Tabela 2: Formas de Organização dos Empreendimentos Econômicos Solidários (EES) na Mesorregião do Triângulo Mineiro e Alto Paranaíba (2017)

\begin{tabular}{lcc}
\hline \multicolumn{1}{c}{ Forma de organização dos EES } & Número de EES cadastrados & (\%) \\
\hline Grupo informal & 83 & $43,4 \%$ \\
\hline Cooperativas & 55 & $28,7 \%$ \\
\hline Associações & 39 & $20,4 \%$ \\
\hline Sociedade Mercantil & 14 & $7,3 \%$ \\
\hline TOTAL & 191 & $\mathbf{1 0 0 \%}$ \\
\hline
\end{tabular}

Fonte: CADSOL (2017) Elaboração: Autores (2018).

O predomínio dos grupos informais se justifica em virtude da burocracia enfrentada para a legalização de uma empresa e/ou estabelecimento. Além disso, as dificuldades enfrentadas pelos responsáveis dos empreendimentos, inclusive em outras experiências, demonstram que essa forma de organizá-los é mais acessível.

O processo fundamental para a formação dos grupos informais consiste na inter-relação entre os integrantes do grupo, principalmente no que concerne aos benefícios de um trabalho coletivo, baseado em relações sociais que findam a criação e a efetivação do empreendimento. Grande parte destes empreendimentos localiza-se nas áreas urbanas e dedicam-se a diferentes atividades como a produção artesanal de peças de crochê, bordados, cerâmicas e peças decorativas; de doces; reciclagem de materiais descartados; comercialização de gêneros alimentícios e a prestação de serviços, a exemplo de lavanderias comunitárias.

Diferente dos grupos informais, as cooperativas solidárias situam-se principalmente no meio rural, possuem um diferencial em relação às outras formas de organização. Nas pesquisas de campo, verificouse elevada densidade de homens que se dedicam ao trabalho nos empreendimentos cooperados. De acordo com os entrevistados, a força braçal é o diferencial na classificação e no processamento dos produtos primários, por isso o predomínio de homens. As mulheres cooperadas se responsabilizavam pelo gerenciamento e aquisição de sementes e de outros insumos. Há, portanto, uma nítida divisão de trabalho, por gênero, nesta forma de organização.

$\begin{array}{llllll}\text { Caminhos de Geografia } & \text { Uberlândia - MG } & \text { v. 19, n. } 67 & \text { Set/2018 } & \text { p. 349-360 } & \text { Página } 357\end{array}$


As associações, que correspondendo por $20,4 \%$ dos EES da mesorregião, são estabelecidas por se tratar de uma forma de organização mais próxima de um setor jurídico. Reúne indivíduos que compartilham dos mesmos objetivos, superando problemas e alcançando sua inserção social e econômica através da Economia Solidária. Assim, destacamos sua importância pela necessidade de legalizar a união entre os associados que, individualmente, não desfrutariam das mesmas condições que experimentam nos empreendimentos econômicos solidários.

Esse tipo de organização geralmente possui caráter filantrópico para com moradores, em defesa da vida, da cultura, dos aspectos sociais, de classe e de trabalho, o que lhes confere um caráter mais amplo quando comparadas às demais formas de organização (CATTANI, 2003). Dependendo do tipo de trabalho, podem assumir características equivalentes às cooperativas populares, cuja participação de mulheres e de homens associados se apresenta em números antagônicos.

Durante a análise dos dados obtidos junto à plataforma on-line do CADSOL, verificou-se que nos EES com um número de até vinte sócios há um predomínio de associados do sexo feminino. Nestes, a principal atividade desenvolvida é a produção artesanal, com destaque para bordados, crochê, produção de doces e de costura. Esses dados devem ser analisados com cuidado, pois a depender da mesorregião estudada, o caráter do empreendimento poderá se diferenciar, como exemplo dos EES situados na mesorregião do Triângulo Mineiro e Alto Paranaíba, cuja dinamicidade das formas de organização se apresenta por múltiplas categorias de atividades econômicas.

Essas categorias, quando apresentadas a partir do recorte espacial aqui proposto (Mesorregião do Triângulo Mineiro e Alto Paranaíba), se difundem pela gama de atividades econômicas que foram encontradas durante a obtenção dos dados via CADSOL e SENAES/TEM e pesquisa de campo.

De acordo com os dados divulgados pela SENAES (2017), 54\% das categorias de atividades econômicas desenvolvidas nos empreendimentos da mesorregião baseiam-se na produção de leite e derivados, fabricação de farinha de mandioca e derivados, criação de peixes e afins, artesanato e bijuterias entre outros; a segunda categoria mais representativa ( $25 \%$ dos EES) é a de comercialização de produtos produzidos nos empreendimentos, com destaque para biscoitos e bolachas, ervas aromáticas e medicinais, suvenires, bijuterias e artesanatos, produtos decorativos em cerâmica etc.; outros $18 \%$ representam atividades de prestação de serviço e trabalho a terceiros, como: lavagem de roupas, oferecimento de reforço escolar para alunos de educação básica, reciclagem de plásticos, fabricação de calçados, cultivos de oleaginosas por tempo determinado, entre outros; os 3\% restantes relacionam-se a consumo de bens e serviços; também foram encontrados cadastros que não ofereciam informações sobre a descrição das atividades que eram desenvolvidas nos respectivos empreendimentos.

Com relação ao gênero dos associados que compõem os empreendimentos da mesorregião, num total de 7.158 associados, 3.851 são homens (54\%) e 3.307 são mulheres (46\%). Os números revelam o caráter dos empreendimentos locais onde há um predomínio dos que se localizam em áreas rurais e produzem alimentos e produtos agrícolas.

Os dados analisados via CADSOL revelam ainda que, dos 191 empreendimentos da Mesorregião do Triângulo Mineiro e Alto Paranaíba, cadastrados no ano de 2017, apenas 124 apresentavam conteúdos referentes à sua área de atuação, resultando em um déficit de 67 empreendimentos ausentes de informações que poderiam vir a ser exploradas. Assim, pode-se concluir que, em princípio, nos empreendimentos econômicos solidários que apresentaram informações, todos tiveram como resultado a realização efetiva de atividades econômicas que promovem a "democratização da economia a partir do engajamento dos cidadãos" (LAVILLE, p. 85, 2001).

Constata-se, portanto, que as particularidades de cada região moldam o meio de produção local e expressam características, saberes, tradições e culturas dos indivíduos e grupos de pessoas que compõem os empreendimentos econômicos solidários.

\section{CONSIDERAÇÕES FINAIS}

O crescimento pelo qual a economia solidária tem passado no Brasil, através das suas diferentes formas de organização, principalmente na mesorregião do Triângulo Mineiro e Alto Paranaíba, deve-se fundamentalmente pelos incentivos governamentais que estimula a criação de empreendimentos solidários. Apesar disso, é importante salientar que tanto esses empreendimentos quanto os trabalhadores inseridos nessa prática ainda enfrentam problemas relacionados à ausência de políticas públicas e atenção de órgãos estaduais e municipais.

$\begin{array}{llllll}\text { Caminhos de Geografia } & \text { Uberlândia - MG } & \text { v. 19, n. } 67 & \text { Set/2018 } & \text { p. 349-360 } & \text { Página } 358\end{array}$


Não obstante, há inúmeros desafios enfrentados pela economia solidária. Ainda assim ela constitui como uma alternativa contrária ao sistema capitalista, por proporcionar oportunidades para indivíduos que seriam excluídos pelo mercado de trabalho convencional. Tais oportunidades podem ser observadas a partir do momento em que o poder público cria incentivos com a finalidade dos grupos desenvolverem atividades de produção, de comercialização e de consumo nos empreendimentos. Nesse processo, o Estado reconhece a economia solidária, a importância dos empreendimentos econômicos solidários para uma parcela significativa de brasileiras e brasileiras que encontram nessa prática formas de sobrevivência, de dignidade e de respeito.

As políticas públicas, voltadas à Economia Solidária, devem compor a agenda dos governantes como uma forma de governança, de soberania e de segurança alimentar. Pois, a partir desta prática pode-se criar condições de desenvolvimento humano, social e econômico dentro dos princípios democráticos de direito.

Para a mesorregião do Triângulo Mineiro e Alto Parnaíba, observou-se que esta apresenta uma dinâmica muito peculiar que favorece a expansão dos empreendimentos econômicos solidários. Existem muitas propriedades de grandes extensões voltadas para a monocultura e ao agronegócio na mesorregião. Por outro lado, as atividades terciárias e secundárias têm requerido menor número de postos de trabalhos ou maior qualificação profissional. Nesse sentido, verifica-se o aumento do número de EES, pois, conforme salientado, a prática da economia solidária consiste numa importante forma de geração de emprego e de renda.

Na mesorregião estudada, verificou-se também que os empreendimentos nela localizados são voltados para a produção de gêneros alimentícios, de artesanato e de prestação de serviços financeiros e comunitários. Outro dado que chamou a atenção foi o número de homens nos empreendimentos, ligeiramente maior do que o de mulheres, diferentemente dos dados apresentados pelo estado.

Dado ao caráter burocrático para a implantação de qualquer empreendimento no Brasil, no Triângulo Mineiro e Alto Paranaíba há um predomínio de EES organizados como grupos informais. Ressalta-se ainda que, a microrregião de Uberlândia, composta por dez municípios, concentra o maior número de empreendimentos, justificado, inclusive, pelos projetos de pesquisa e extensão desenvolvidos na Universidade Federal de Uberlândia (UFU) que muito têm contribuído para a formalização dos empreendimentos, catalogação e incentivos aos grupos que buscam nesta prática uma forma de sobrevivência mais digna.

Conclui-se que os desafios são muitos. Embora sejam visíveis alguns avanços, tal como a possibilidade de realizar o trabalho com liberdade e de forma um pouco mais autônoma, ainda há um longo caminho a ser percorrido, para que muitos indivíduos e grupos possam viver de forma verdadeiramente digna, por meio do seu trabalho.

\section{AGRADECIMENTOS}

Os autores agradecem os recursos recebidos da Fundação de Amparo à Pesquisa de Minas Gerais FAPEMIG, os quais possibilitaram a realização da pesquisa desenvolvida. Destacamos, ainda, que este artigo é resultado do Projeto de Pesquisa PPM/FAPEMIG (Edital 02/2015, Processo PPM0009015) e o Projeto de Pesquisa de Iniciação Científica - PIBIC/FAPEMIG/UFU 2017-2018.

\section{REFERÊNCIAS}

ARRUDA, M. Tornar real o possível: a formação do ser humano integral, economia solidária, desenvolvimento e o futuro do trabalho. Petrópolis, RJ: Vozes, 2006, 365p.

AZAMBUJA, L.R. Os valores da Economia Solidária. Sociologias. Porto Alegre, ano 11, n. 21, p. 282-317, jan/jun 2009.

CADASTRO NACIONAL DE EMPREENDIMENTOS ECONÔMICOS SOLIDÁRIOS E COMÉRCIO JUSTO. Boletim Informativo. CADSOL, 2018. Disponível em: <http://cadsol.mte.gov.br/inter/cadsol/main.seam >. Acesso em 24 julho de 2018.

CATTANI, A. D. A Outra Economia: os conceitos essenciais. In. CATTANI, A. D. (org.). A outra Economia. Porto Alegre: Veraz Editores. 2003.

FRANÇA FILHO, G. C. et al (Orgs.). Ação Pública e economia solidária: uma perspectiva internacional. Porto Alegre: Editora UFRGS, 2006, p. 201-206.

$\begin{array}{llllll}\text { Caminhos de Geografia } & \text { Uberlândia - MG } & \text { v. 19, n. } 67 & \text { Set/2018 } & \text { p. 349-360 } & \text { Página } 359\end{array}$


GAIGER, L. I. A dimensão empreendedora da economia solidária: notas para um debate necessário. Outra economia, v. 2, n. 3, 2011, p. 58-72.

INSTITUTO BRASILEIRO DE GEOGRAFIA E ESTATÍSTICA (IBGE). Disponível em: $<$ http://www.ibge.gov.br>. Acesso em 14 de junho de 2018.

LEMES, F. R. M. A inserção da economia solidária no mercado: contradições e possibilidades. Outra Economia, v. 2, n. 2, p. 52-67, 2008.

LAVILLE, J. L. Economia solidária, a perspectiva europeia. Sociedade e Estado. Brasília, v. 16, n. 1, p. 57-99, jun./dez. 2001.

MARX, K. O capital. Livro 3. 2.ed. Trad. Wenceslau Roces. México: Fondo de Cultura Económica, 1968. MINISTÉRIO DO TRABALHO E EMPREGO. Economia Solidária. Brasília, 2017. Disponível em: <http://trabalho.gov.br/trabalhador-economia-solidaria>. Acesso em: 26 de julho de 2018.

POCHMANN, M. Economia Solidária no Brasil: possibilidades e limites. Universidade Federal de Campinas, p. 23-34, ago. 2004.

SANTOS, M. Por uma outra globalização. Rio de Janeiro: Record, 2000.

O espaço dividido: os dois circuitos da economia urbana nos países subdesenvolvidos. $2^{\mathrm{a}}$. ed. São Paulo: Edusp, 2004.

SECRETÁRIA NACIONAL DE ECONOMIA SOLIDÁRIA (SENAES). Disponível em: http://<www.mte.gov.br>. Acesso em 16 de junho de 2018.

SILVA, E. E.; BORBA, E. L.; MACHADO, J. C. A lei de economia solidária do município de Lavras/MG: avanços ou limitações no enfrentamento da pobreza e exclusão social? Revista Espacios (Caracas), v. 37, p. 1-20, 2016.

SILVA, R. R. da; CLEPS, G. D. G. Socioeconomia solidária: a expansão na mesorregião do Triângulo Mineiro e alto Paranaíba. Revista em Extensão, v. 10, p. 73-84, 2011.

SINGER, P. A consistência das redes solidárias. São Leopoldo, Ciências Sociais: UNISINOS, v. 37, n. 159, p. 177-204, 2001.

Economia Solidária. In: CATTANI, A.D. A outra economia. Porto Alegre: Veraz Editores, 2003.

Recebido em: 27/02/2017

Aceito para publicação em: 04/10/2018 